\title{
ASSESSMENT OF SILVER METAL RELEASED INTO WASTEWATER AFTER USING A SILVER DEODORANT
}

\author{
LEBOGANG L. M. MODIKA, LUFUNO MATSHEKETSHEKE \& JABULANI RAY GUMBO \\ Department of Hydrology and Water Resources, University of Venda, South Africa
}

\begin{abstract}
The purpose of the research was to assess availability of silver based deodorant and to assess the levels of nanosilver particles that are released into bathwater. A survey was conducted to assess the availability and affordability of silver based deodorants in Thohoyandou and Louis Trichardt. The survey studies showed that the silver based deodorants are available in commercial stores and pharmacies. The price range was from R16.99 to R25.00. Nivea silver protect deodorant was applied to the body. In Louis Trichardt town, the wastewater samples were collected just below the shower head (SH) and just before entry to sewer system (SS) and then filtered through a membrane filter $(0.45 \mu \mathrm{m})$ and through a Whatman filter paper. The residue on the Whatman filter paper was then acid digested and then analyzed for silver content. Two analytical methods, atomic absorption spectroscopy (AAS) and inductively coupled plasma optical emission spectroscopy (ICP OES) were used for the analysis of the silver content. The AAS results showed that municipal water, bath water at SH and SS was zero and the Nivea silver protect deodorant was $0.5 \pm 0.0 \mathrm{ppm}$. The ICP OES results showed that the silver content of the municipal water was $<0.005 \mathrm{ppm}$ and the Nivea silver protect deodorant was $0.3 \mathrm{ppm}$. The bath water at SH and SS, the ICP OES, showed that the silver content was $<0.005 \mathrm{ppm}$. However the acid digested residue showed that the silver content was $0.01 \mathrm{ppm}$ at 2 metres and $<0.005 \mathrm{ppm}$ for 0 metres. The ion chromatographic analysis indicated that the municipal water had trace levels of fluoride (F) ions, SH had $6.01 \mathrm{ppm}$ of F, SS had $3.25 \mathrm{ppm}$ of F and the soap A had $2.10 \mathrm{ppm}$ of F. The retained residue was established to be silver trifluoride $\left(\mathrm{AgF}_{3}\right)$ with the use $\mathrm{X}$-ray diffraction technique. Thus, the silver nanoparticles are a potential hazard to the microbial community resident at municipal sewage treatment plant and aquatic ecosystem.
\end{abstract}

Keywords: wastewater, silver particles, environmental hazards, bath soap.

\section{INTRODUCTION}

Globally, nanoproducts fabricated using nano-scale materials have dramatically increased from about 200 in March 2002 to approximately 1628 by 2018 [1]. However, although the number of engineered nanomaterials (ENMs) applications has increased dramatically, their potential effects to humans and other ecological systems are limited and disjointed. This has raised concerns on the potential risks of ENMs to humans and other ecological systems by diverse stakeholder groups. This challenge is compounded by lack of well-defined mechanisms, procedures, and protocols for conducting robust risk assessment of ENMs in a given environmental media.

The increasing use of silver nanoparticles (AgNPs) in textiles, washing machines, cosmetics, and deodorants - due to their antibacterial properties - has exacerbated their release into the sewer systems [2]. Recent studies have identified $\mathrm{AgNP}$ and $\mathrm{Ag}^{+}$ions in socks wash water [3] and found nanosized $\mathrm{AgCl}$ particles [4] in laundry wash water and $\alpha-\mathrm{Ag}_{2} \mathrm{~S}$ in sewage sludge samples [5] and Ag tooth brush and tooth brush mouth wash water [6]. A study by Shamuyarira and Gumbo [7] found presence of silver in municipal sludge for the towns of Louis Trichardt and Thohoyandou at levels of $21.93 \pm 0.38 \mathrm{mg} / \mathrm{kg}$ dry mass and $6.13 \pm 0.12 \mathrm{mg} / \mathrm{kg}$ dry mass respectfully indicating the use of silver products in these towns. However, presently there are limited studies on the fate of AgNPs in sewer water [8] - a component of wastewater treated in wastewater treatment plants (WWTPs). Here, 
preliminary findings on the assessment of Ag NPs in wastewater from shower wash water sampled in Limpopo Province (Makhado urban settlement) are presented. Nivea Silver Protect (silver based deodorant) (www.nivea.co.za) was used as a source of Ag NPs in our study. To simulate actual application scenario, the deodorant was applied to the human body in accordance to the prescribed daily product use. The water samples were collected at shower head (SH) (municipal drinking water) and just before entry into the sewer system (SS) after a shower. The specific objectives were: (i) to determine the total $\mathrm{Ag}+$ in $\mathrm{SH}$ and SS using atomic absorption spectroscopy (AAS) and inductively coupled plasma optical emission spectroscopy (ICP-OES); (ii) to determine the source of fluoride (Ion chromatography) in the SH and SS; and (iii) to identity and characterize the Ag NPs in the SS using the X-ray diffraction (XRD) techniques.

\section{MATERIALS AND METHODS}

\subsection{Characteristics of the study area}

The study area was the Thohoyandou town which is located under the Thulamela municipality and Louis Trichardt town which is located under Makhado municipality in the Vhembe region. The Vhembe region extends northwards to the Limpopo River that forms the boundary between South Africa and Zimbabwe. It lies between the latitudes $20^{\circ} 50^{\prime}$ and $23^{\circ} 45^{\prime}$ south and longitudes $29^{\circ} 50^{\prime}$ and $30^{\circ} 30^{\prime}$ east. It is situated about $70 \mathrm{~km}$ east of Louis Trichardt and about $5 \mathrm{~km}$ south of Sibasa [9]. Thohoyandou is a small town and it is over populated, and people around Thohoyandou including tertiary students are using different types of deodorants of which some contains Nano silver.

\subsection{Survey study}

The shops and pharmacies which sell silver products were visited and questions such as which of deodorant is selling more than others was asked and the answers were recorded on questionnaire form. Voluntary consent was sort from the representative of the outlet and codes were used to hide the outlet identity. The study was carried out in August 2011 and April 2018.

\subsection{Sample collection}

Sample A is the sunlight bath soap and it cut into small pieces and $10 \mathrm{mg}$ of the power was transferred to $100 \mathrm{ml}$ volumetric flask and made up to the mark with deionised water for anion analysis.

The water samples were collected from a house in Louis Trichardt (Makhado town). The water samples were collected in $250 \mathrm{ml}$ plastic bottles (VWR International $\mathrm{GmbH}$, Darmstadt). The water samples were composed of bath water (municipal water supply) and wash water. The wash water was collected after the person had taken a normal bath (prior to which the person had applied nanoSilver deodorant. The Nivea silver deodorant was applied on the human body and later washed off, the wash water was collected just below the shower head $(\mathrm{SH})(0 \mathrm{~m})$ and just before entry to the sewer systems $(\mathrm{SS})(1 \mathrm{~m})$. The samples were filtered using filter paper $0.45 \mu \mathrm{m}$ membrane (cellulose acetate, Sartorius) and the clear filtrate was apportioned into two subsamples for the measurement of ionic Ag content using, atomic absorption spectroscopy (AAS) and inductively coupled plasma optical emission spectroscopy (ICP-OES) and anion analysis. The membrane was then dried under room 
temperature protected from light. The retained residues on the membrane filter was then analysed using X-ray diffraction technique. The clear filtrates SH and SS and municipal water were analysed for anions using ion chromatographic technique.

$10 \mathrm{ml}$ of Nivea silver protect deodorant was transferred to $100 \mathrm{ml}$ and made up to the mark with deionised water. The anions in the Nivea silver protect deodorant were determined using ion chromatographic technique.

The bath soap A or B was cut in to small pieces and $10 \mathrm{mg}$ of soap pieces were transferred to $100 \mathrm{ml}$ and made up to the mark with deionized water. The flask was shaken until the soap had totally dissolved. The anions in the soap were determined using ion chromatographic technique.

\subsection{Sample analysis}

\subsubsection{Silver analysis}

The water samples were first filtered through a $0.45 \mu \mathrm{m}$ membrane filters (cellulose acetate, Sartorius). The Varian AAS (Spectra AA220) (University of Venda) and ICP-OES (Vista Pro CCD simultaneous model, available at CSIR, Pretoria) was also employed in the determination of $\mathrm{Ag}$ content of the wash water and content of the deodorants. The $\mathrm{pH}$, electrical conductivity and turbidity of the water samples were also determined.

The extraneous material that was retained on the membrane filter was acid digested $\left(\mathrm{HNO}_{3}\right.$ only) as per procedure of Kimbrough and Wakakuwa [10] and analyzed using the AAS and ICP-OES instruments.

\subsubsection{Anion analysis}

Ion chromatography (Dionex Ion) is used for water chemistry analysis. IC is able to concentration of major anions, such as fluoride, chloride, nitrate, nitrite, and many other elements. Concentration of organic acid can also concentration of organic acid can also be measured. IC measure concentration of ionic species by separating them based on their interaction with resin. The calibration of IC was done using the standards if $1 \mathrm{ppm}, 5 \mathrm{ppm}$, $10 \mathrm{ppm}$, and $20 \mathrm{ppm}$ as per manufacturer's instructions.

\subsubsection{XRD analysis}

$\mathrm{X}$-ray diffraction (XRD) is a versatile, non-destructive technique that reveals detailed information about the chemical composition and crystallographic structure of natural and manufactured materials. The samples were prepared for XRD analysis using a back-loading preparation method. Then we analysed using PANalyticalX'pert pro powder diffractometer with X'Celarator detector (University of Pretoria) and variable divergence- and receiving slits with Fe filtered Co-k $\alpha$ radiation. The phases were identified using X' Pert Highscore plus software.

\subsection{Data analysis}

Using Microsoft Excel, simple statistics (means) were carried out and graphs were drawn.

\section{RESULTS AND DISCUSSION}

3.1 Survey on the types of nanoproducts that are used in Thohoyandou and Makhado Towns

The research findings show that they are few people around Thohoyandou and Louis Trichardt who are familiar or use nano silver deodorants as deduced from the usage of the 
nanoproducts. There was a range of silver nanoproducts that were found in the study area. The questionnaire asked about the quantity of nanoproducts that are sold per year and this ranged from 36 to 312 in Thohoyandou and from 0 to 272 per year in Louis Trichardt (Fig. 1). This appears to be very little in comparison to other deodorants which do not contain silver. The following are the results obtained during survey questionnaire on silver nanoproducts' usage in the study area. The price range of silver nanoproducts was from R16.99 to R25.00 in 2011 and R8.99 to R99.99 in 2018 from the retail outlets and silver protect deodorant were dominant (Fig. 2). There was a $76 \%$ increase in the range and types of silver based personal care products (Fig. 3) indicating the continued use of silver based products by the residents. New products containing silver have been introduced such as shower gel, aftershave and bath soaps. The study of Shamuyarira and Gumbo [7] confirmed the presence of silver in the municipal sludge for Louis Trichardt and Thohoyandou towns.

\subsection{The release of silver ions from commercial deodorant into wash water}

The ICP OES instrument was able to detect the presence of $\mathrm{Ag}^{+}$in the water samples and the municipal water supply, as expected, did not have any silver nanoparticles less than 0.005 ppm (Table 1). The content of silver from the deodorant was found to be $0.03 \mathrm{ppm}$. The analysis of the wash water, initially, also did not yield any silver nanoparticles, less than $0.005 \mathrm{ppm}$. However the upon filtering the wash water and carrying out acid digestion of retained residues indicated the presence of silver nanoparticles at $0.01 \mathrm{ppm}$ level. Interestingly the acid digestion of wash water sample at zero meter indicated that silver content was less than $0.005 \mathrm{ppm}$. On the other hand the wash water at 1 metre (acid digested)

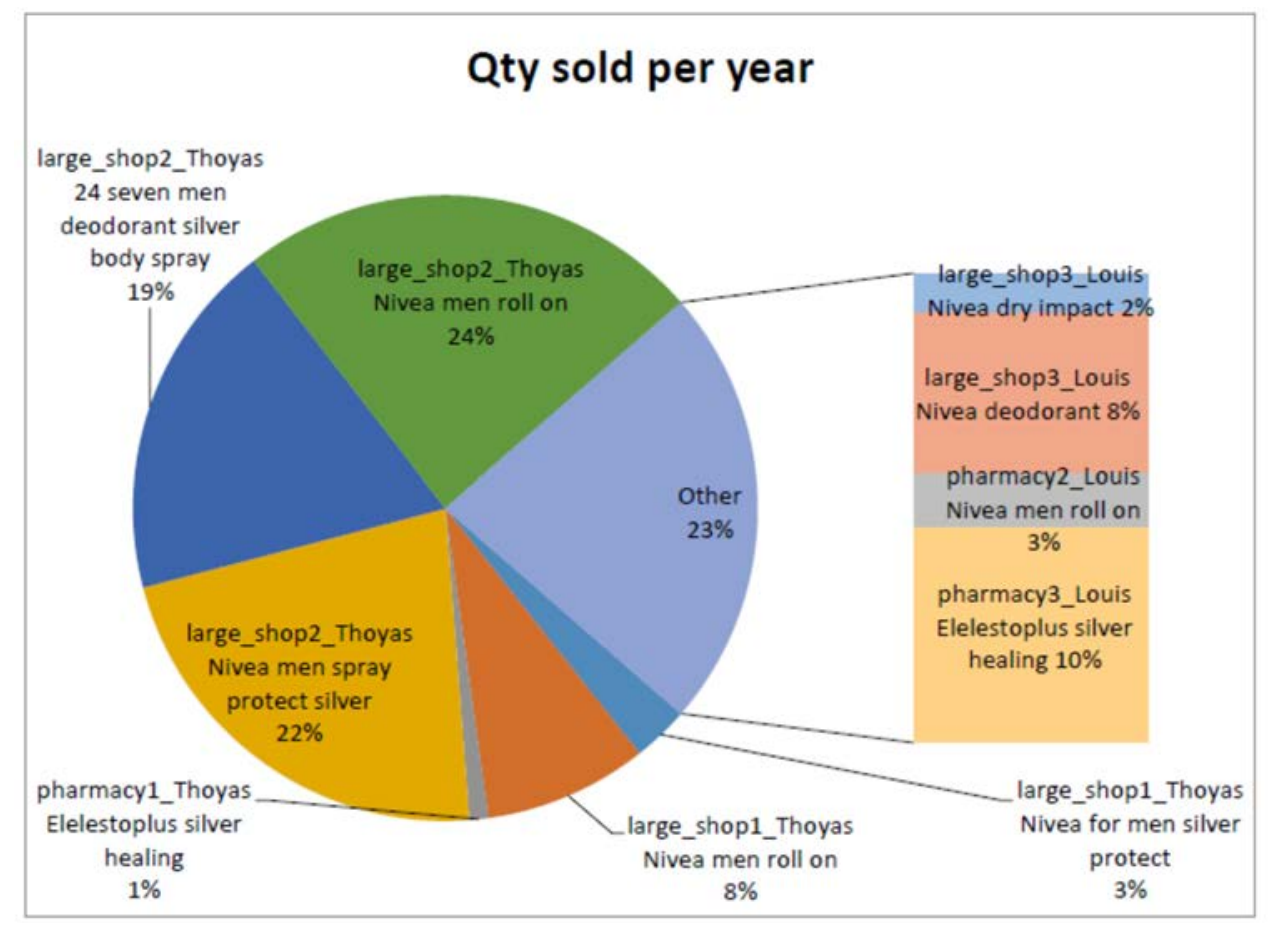

Figure 1: The silver nanoproducts sold in Louis Trichardt and Thohoyandou retail outlets. 


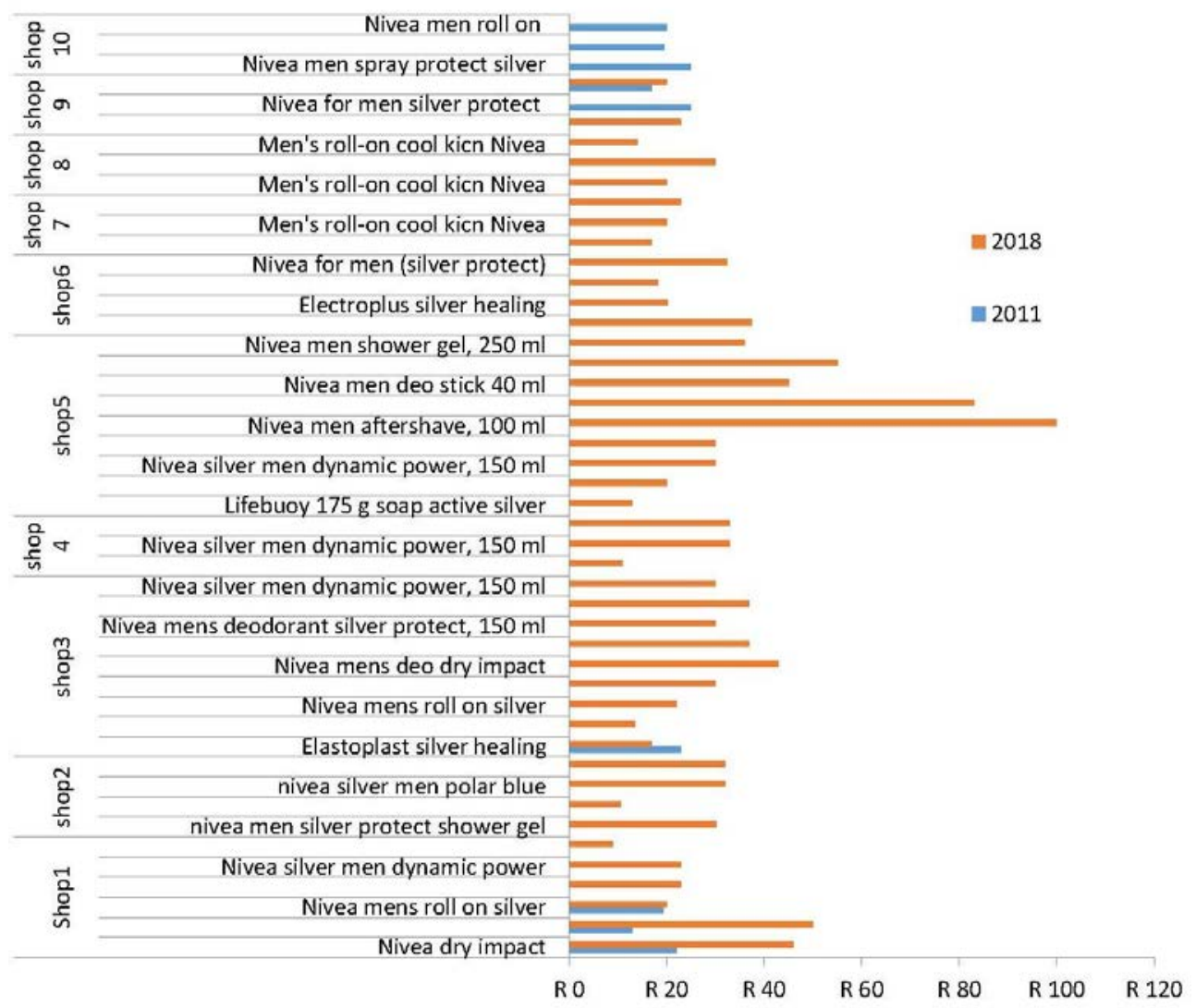

Figure 2: The price of different silver nanoproducts in the study area. (In 2011, USD1=R7.)

Table 1: The Ag (ppm) in the samples.

\begin{tabular}{|l|l|c|}
\hline & AAS & ICP OES \\
\hline Municipal water & 0.00 & $<0.005$ \\
\hline Wastewater at $0 \mathrm{~m}$ & 0.00 & $<0.005$ \\
\hline Wastewater at $1 \mathrm{~m}$ & 0.00 & $<0.005$ \\
\hline $\begin{array}{l}10 \mathrm{ml} \text { of deodorant to } 100 \mathrm{ml} \text { of } \\
\text { deionised water }\end{array}$ & 0.05 & 0.03 \\
\hline Acid digested filtrate & & 0.03 \\
\hline
\end{tabular}

showed the presence of $\mathrm{Ag}^{+}$at $0.01 \mathrm{ppm}$ levels. The AAS method did not detect any levels of $\mathrm{Ag}^{+}$that were greater than $0.05 \mathrm{ppm}$ in the municipal or bath waters (Table 1). However, the AAS method was able to detect appreciable levels of $\mathrm{Ag}^{+}$that were present in the silver protect deodorant. 
The analysis under this method, ICP OES, may indicate the presence of silver in wastewater as it enters the sewer systems. The study of Shamuyarira and Gumbo (2016) confirmed the presence of silver in the Louis Trichardt municipal sludge.

During the transportation of wastewater towards the wastewater treatment plant, there may be leakages which may end up in aquatic ecosystems. Musee et al. [11] showed that the widespread exposure to silver may impact and disrupt health of the aquatic ecosystem. For example, nitrifying bacteria that are resident in the sewage treatment plants (STPs) are there to convert nitrogenous compounds in raw sewage into less harmful products and some nitrifying bacteria (ammonia oxidizing bacteria) were susceptible to $35 \mathrm{~nm}$ AgNPs (40 ppm) than nitrite oxidizing bacteria [12]. The toxicity of nanosilver to these organisms has raised concerns that release of nanosilver to the environment may disrupt the operation of STPs as well as natural processes in the ecosystem that support plant life. According to Naik and Kowshik [13] the $\mathrm{Ag}^{+}$range concentration of 1 to $10 \mu \mathrm{mol} / \mathrm{l}$ and AgNPs size 7 to $20 \mathrm{~nm}$ of range 0.78 to 6.25 and $12.5 \mu \mathrm{g} / \mathrm{ml}$ was required to cause kill or damage bacteria in water.

\subsection{The composition of anions in samples and formation of silver trifluoride}

The research findings show that there are variable compositions in anionic content of the bath soaps, municipal water, wastewater and silver deodorant (Table 2). The ion chromatographic analysis showed no presence of fluoride $(\mathrm{F})$ in the municipal water and in the deodorant. With the bathing soap A, there were high levels of fluoride, as shown by $6.01 \mathrm{ppm}$ of $\mathrm{F}$ in shower head (SH) wash water and 3.25 ppm of $F$ wash water in the sewer system (SS). This may indicate that soap A was the likely source of $\mathrm{F}$ in the wash water (Table 2).

The retained residue in the $0.45 \mu \mathrm{m}$ membrane filter was then investigated using XRD technique for identity of silver nanoparticle (AgNP). The Ag phases were identified using X'Pert Highscore plus software. The AgNPs phase in the SS was established as silver trifluoride $\left(\mathrm{AgF}_{3}\right)$ (Fig. 3). The studies of Grochala [14] and Song and Tian [15] confirmed the existence of $\mathrm{AgF}_{3}$. We postulate that the $\mathrm{AgF}_{3}$ were formed in situ during the transportation process into the sewer system through (bio) chemical reactions involving $\mathrm{Ag}^{+}$ and $\mathrm{F}^{-}$, but further investigations are needed to explicitly elucidate the underlying mechanisms.

The research findings provide insights on the fate of Ag NPs in the environment and suggested the possibility of $\mathrm{AgF}_{3}$ formation. Moreover, there is also a likelihood of $\mathrm{Ag}^{+}$or nano-AgF (possible use in dental medications) are known to be toxic to microorganisms [13], [16]. Overall, our results have provided insights on the: (i) feasibility of using the ICP-OES technique for the identification of low concentrations of total $\mathrm{Ag}^{+}$primarily due to $\mathrm{Ag}$ NPs in a sewer system, although has inability to isolate the ionic and zero valent silver components; (ii) likely transformation of the Ag NPs after their release into the environment after interactions with other chemical species; and (iii) need to exercised caution to avoid

Table 2: The composition and concentration of anions in samples.

\begin{tabular}{|l|c|c|c|c|}
\hline & Fluoride & Chloride & Nitrate & Sulphate \\
\hline Municipal water & --- & $14.25 \pm 0.69$ & --- & $7.99 \pm 2.28$ \\
\hline Soap A & $2.34 \pm 1.15$ & $4.78 \pm 2.78$ & $1.35 \pm 0.80$ & $0.14 \pm 0.09$ \\
\hline Silver deodorant & --- & $205.03 \pm 50.21$ & --- & $0.07 \pm 0.02$ \\
\hline Wastewater $(0 \mathrm{~m})$ & $6.01 \pm 0.89$ & $58.73 \pm 2.93$ & --- & $5.79 \pm 2.28$ \\
\hline Wastewater $(1 \mathrm{~m})$ & $3.25 \pm 0.05$ & $62.66 \pm 0.66$ & $0.24 \pm 0.29$ & --- \\
\hline
\end{tabular}

Notes: --- not detected. 

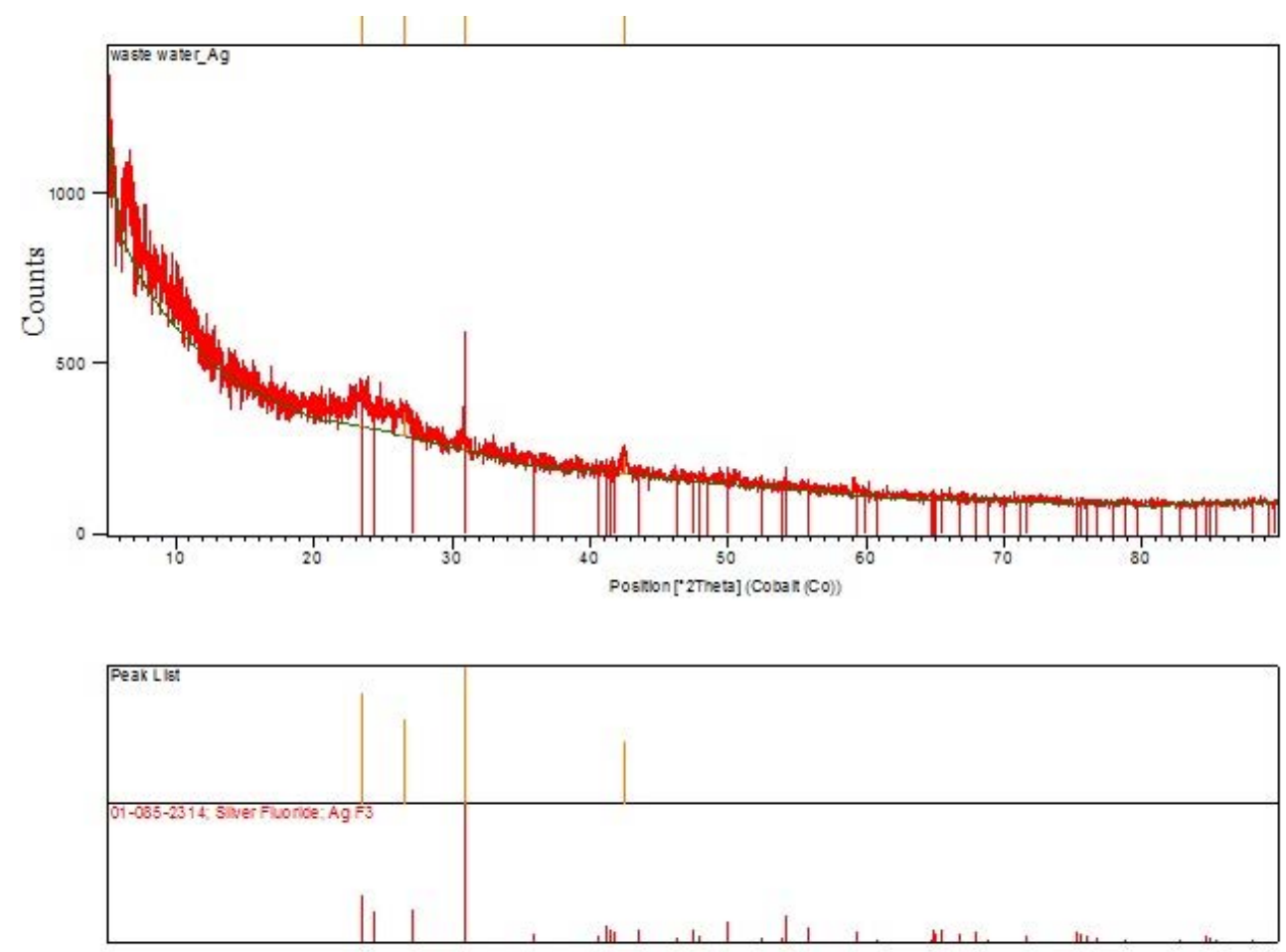

Figure 3: Analysis of SS sample for silver trifluoride.

speculation on the potential interactions of NPs with organisms after entry into the environment, because of yet to be fully known transformations, and dissolution processes that may transform the NPs considerably. The study of Folens et al. [17] proposed that as silver bearing ores are dwindling worldwide it is economic feasible to recover $\mathrm{Ag}$ in wastewater or in sludge and also promote the recovery of $\mathrm{Ag}$ instead of disposal in wastewater and help protect the environment.

\section{CONCLUSION}

A survey was conducted to assess the availability and affordability of silver based deodorants in Thohoyandou and Makhado and the price range was from R16.99 to R25.00. The survey studies showed that the silver based deodorants are available in commercial stores and pharmacies. In this study a deodorant was assessed for the silver content and potential to release silver into wastewater and harm the aquatic environment.

\section{RECOMMENDATION}

This research showed that over time, the silver particles are more likely to enter the water systems and end up in the sewage treatment plants. Nanosilver must be classified as at least a pesticide in order for it to be well managed. This can be a very beneficial move for South Africa because the release of Ag will be managed for the time being before their actual impacts on the environment are known. 


\section{ACKNOWLEDGEMENT}

This work was supported by Department of Science and Technology and CSIR, Natural Resources and the Environment (contract research project E057) under the auspices of the Development of Health, Safety and Environmental Research Platform for Nanosciences and Nanotechnologies in South Africa.

\section{REFERENCES}

[1] Vance, M.E., Kuiken, T., Vejerano, E.P., McGinnis, S.P., Hochella Jr, M.F., Rejeski, D. \& Hull, M.S., Nanotechnology in the real world: Redeveloping the nanomaterial consumer products inventory. Beilstein Journal of Nanotechnology, 6, p. 1769, 2015.

[2] Mbedzi, A. \& Gumbo, J.R., The release of silver and aluminum into wastewater from commercially available silver spray deodorant and soap B. Proceedings of International Conference on Advances in Science, Engineering, Technology and Natural Resources (ICASETNR-16),pp. 147-151, 2016.

[3] Benn, T.M. \& Westerhoff, P., Nanoparticles silver released into water from commercially available sock fabrics. American Chemical Society, 42, pp. 4133-4139, 2008.

[4] Mitrano, D.M., Rimmele, E., Wichser, A., Erni, R., Height, M. \& Nowack, B., Presence of nanoparticles in wash water from conventional silver and nano-silver textiles. ACS Nano, 8(7), pp. 7208-7219, 2014.

[5] Kim, B., Park, C.S., Murayama, M. \& Hochella Jr, M.F., Discovery and characterization of silver sulfide nanoparticles in final sewage sludge products. Environmental Science \& Technology, 44(19), pp. 7509-7514, 2010.

[6] Mackevica, A., Olsson, M.E. \& Hansen, S. F., The release of silver nanoparticles from commercial toothbrushes. Journal of Hazardous Materials, 322, pp. 270-275, 2017.

[7] Shamuyarira, K.K. \& Gumbo, J.R., Assessment of heavy metals in municipal sewage sludge: A case study of Limpopo Province, South Africa. International Journal of Environmental Research and Public Health, 11(3), pp. 2569-2579, 2014.

[8] Musee, N., Alan, C. \& Peter, J., A South African research agenda to investigate the potential environmental health and safety risk of nanotechnology. South African Journal of Science, 106, pp. 3-4, 2010.

[9] State of Rivers Report (SRR), Letaba and Luvuvhu river system. WRC report no TT165/01, Water Research Commission, Pretoria, 2001.

[10] Kimbrough, D.E. \& Wakakuwa, J.R., Acid digestion for sediments, sludges, soils and solid wastes.A proposed alternative to EPA SW 846 Method 3050. Environmental Science \& Technology, 23(7), pp. 898-900, 1989.

[11] Musee, N., Zvimba, J.N., Schaefer, L.M., Nota, N., Sikhwivhilu, L.M. \& Thwala, M., Fate behavior of $\mathrm{ZnO}$-and Ag-engineered nanoparticles and a bacterial viability assessment in a simulated wastewater treatment plant. Journal of Environmental Science and Health, Part A, 49(1), p. 59-66, 2014.

[12] Yang, Y., Li, M., Michels, C., Moreira-Soares, H. \& Alvarez, P.J., Differential sensitivity of nitrifying bacteria to silver nanoparticles in activated sludge. Environmental Toxicology and Chemistry, 33(10), pp. 2234-2239, 2014.

[13] Naik, K. \& Kowshik, M., The silver lining: towards the responsible and limited usage of silver. Journal of Applied Microbiology, 2017.

[14] Grochala, W., On possible existence of pseudobinary mixed valence fluorides of Ag (I)/Ag (II): a DFT study. Journal of Molecular Modeling, 17(9), pp. 2237-2248, 2011. 
[15] Song, C. \& Tian, Z., First principles study on the size evolution and stability of (AgF) $\mathrm{n}(\mathrm{n}=1-12)$ clusters. Computational and Theoretical Chemistry, 1074, pp. 157-162, 2015.

[16] Silva, A.V., Mota, C.C., Teixeira, J.A., Lins, E.C., Gomes, A.S. \& Rosenblatt, A., Potential of nano-silver fluoride for tooth enamel caries prevention. Colloidal Nanoparticles for Biomedical Applications XIII, 10507, p. 105071A, International Society for Optics and Photonics, 2018.

[17] Folens, K., Huysman, S., Van Hulle, S. \& Du Laing, G., Chemical and economic optimization of the coagulation-flocculation process for silver removal and recovery from industrial wastewater. Separation and Purification Technology, 179, pp. 145$151,2017$. 